\title{
Requirement of thyroid function for the expression of seasonal reproductive and related changes in red deer (Cervus elaphus) stags
}

\author{
Z. D. Shi and G. K. Barrell \\ Animal and Veterinary Sciences Group, PO Box 84, Lincoln University, New Zealand
}

\begin{abstract}
Summary. The effect of thyroid function on regulation of seasonal reproduction was investigated in three red deer stags thyroidectomized (THX) in summer (January 1988) in comparison with five thyroid-intact controls. Responses of luteinizing hormone ( $\mathrm{LH}$ ) and testosterone to a bolus injection of $10 \mu \mathrm{g}$ gonadotrophin-releasing hormone $(\mathrm{GnRH})$ were tested in July, October, December, February and April. Blood samples were collected at weekly intervals from December 1987 to June 1989 for measurement of testosterone, triiodothyronine (T3) and prolactin concentrations. Testis diameters were measured every 2 weeks. In October 1988 (spring), plasma LH concentrations of control stags were less responsive $(P<0.01)$ to stimulation by $\mathrm{GnRH}$ than those of THX stags; plasma testosterone concentrations and testis diameters were low and there was no increase in plasma testosterone concentrations after injection of $\mathrm{GnRH}$ in control stags during October or December (spring, early-summer). In contrast, THX stags maintained a testosterone response $(P<0.01)$ in these 2 months and did not exhibit any signs of a seasonal lack of reproductive activity at this time of year. Control stags cast antlers in spring whereas THX stags maintained hard antlers throughout the study. Concentrations of plasma T3 were not detected in THX stags from June 1988 onwards, but exhibited a seasonal pattern in control stags, with low concentrations during autumn and winter (April to July) and high concentrations in spring and summer (August to February). There was no effect of thyroidectomy on the seasonal pattern of prolactin secretion. These results show that thyroidectomy blocks the seasonal transition from the breeding to the nonbreeding season in red deer stags and support the hypothesis that thyroid hormones are required for this transition.
\end{abstract}

Ke wwords: thyroidectomy; seasonality; iuteinizing hormone; testosterone; prolactin; red deer

\section{Introduction}

Seasonality of reproductive activity and other physiological events in mammals is presumed to arise from an interaction between endogenous circannual rhythms and a variety of environmental changes, the most important of which is daily photoperiod (Gwinner, 1986; Karsch \& Wayne, 1988). It is firmly established that the link between photoperiodic signals and reproductive responses involves the pineal gland and its secretory product, melatonin (Karsch et al., 1984), but it is not clear how melatonin interacts with other endocrine pathways to produce the seasonal changes. Seasonal breeding is a manifestation of changes in release of luteinizing hormone (LH) and follicle-stimulating hormone (FSH) arising from changes in secretion of gonadotrophinreleasing hormone $(\mathrm{GnRH})$ (Lincoln \& Short, 1980) and changes in the sensitivity of these hormones to negative feedback by gonadal steroids (Legan et al., 1977; Goodman et al., 1982). It is possible that other components of this system include the thyroid hormones; this is suggested by the prolongation of reproductive activity in starlings (Wieselthier \& van Tienhoven, 1972; 
Goldsmith \& Nicholls, 1984), mink (Jacquet et al., 1986) and sheep (Nicholls et al., 1988; Moenter et al., 1991), which occurred after these animals were thyroidectomized. These findings indicate that thyroid function may be required for termination of the annual breeding season.

Red deer stags are mammals with pronounced seasonal reproductive changes. They have a dramatic 'rutting' period, which is related to changes in gonadal function and blood concentrations of reproductive hormones and these are associated with major changes in behaviour, appetite and neck muscle mass. The annual reproductive events are linked to a spectacular cycle of growth, mineralization and casting of antlers, which are bony appendages attached to the frontal bones of the skull.

This study examined the effects of thyroidectomy on seasonal changes in red deer stags and tested whether the procedure would prevent reproductive quiescence in the spring. Some preliminary results of the study have been reported previously (Shi \& Barrell, in press) and the present paper describes findings based on data for $\mathbf{L H}$, testosterone, testis diameter, prolactin and triiodothyronine.

\section{Materials and Methods}

Animals and treatments. Ten 14-month-old red deer stags were allocated to be either thyroidectomized (THX) or nonoperated controls $(n=5)$. Thyroidectomy was performed after sedation with i.m. injection of $30-40 \mathrm{mg} x y$ lazine hydrochloride (Rompun, Bayer) and anaesthesia with i.v. injection of 10-12 mg sodium thiopentone $/ \mathrm{kg}$ live weight (Intraval sodium, May \& Baker) in January 1988. A 4-5 cm medial ventral incision was made through the skin and fascia overlying the trachea. Thyroid glands were located on each side of the trachea and removed following blunt dissection of the superficial muscles and fascia and tying off the thyroid blood vessels. An implant containing $20 \mathrm{mg}$ thyroxine (Glaxo Laboratories (UK) Ltd) was inserted s.c. immediately after surgery. During the next 18 months, all animals grazed outdoors on pasture of predominantly ryegrass and white clover (Lolium perenne and Trifolium repens) on the research farm at Lincoln University, New Zealand. Water was provided ad libitum and the pasture was supplemented with lucerne hay during winter. Of the five surgically treated animals, two proved subsequently to have been only partially thyroidectomized and data from these two animals were excluded from the results.

Every week, stags were herded into a pen and a single $10 \mathrm{ml}$ blood sample was collected by jugular venepuncture while each stag was held by manual restraint. Blood was collected into a glass tube containing 120 units of sodium heparin. After centrifugation at $1000 \mathrm{~g}$, plasma was separated and stored at $-18^{\circ} \mathrm{C}$. Every second week, testicular diameter was measured as the craniocaudal distance between two lightly spring-loaded brass plates held on to the scrotum of standing stags. Response to a bolus i.v. injection of $10 \mu \mathrm{g}$ GnRH (NIAMDD 26-306) was assessed in all three THX and four intact stags in July, October, December, February and April, corresponding to different stages of the antler cycle, i.e. hard antler after rutting, antler casting, antler growth, shedding of velvet and hard antler during rutting, respectively. To facilitate blood sampling, a polyvinylchloride cannula was inserted into a jugular vein and left in place. Samples were drawn at $-30,-15,0,10,20,30,50,70,90,120 \mathrm{~min}$ in relation to GnRH injection.

Hormone assays. Plasma LH concentration was determined using the method of Kelly et al. (1982). Values were expressed in terms of an ovine standard, NIAMDD-LH-S20. Iodinated ovine LH (NIADDK-oLH-1-3) was used as tracer and antiserum was NIADDK-anti-oLH-I (AFP-192279). Assay sensitivity was $0.15 \mathrm{ng} / \mathrm{ml}$ and intra- and interassay coefficients of variation were 6.5 and $13.2 \%$, respectively. Serially diluted deer plasma produced a binding curve which was parallel to that of the ovine standard.

Plasma testosterone concentration was measured by direct radioimmunoassay (Garnier et al., 1978) using a nonextracted technique described by Schanbacher \& D'Occhio (1982). This assay used $\left[1,2,6,7,-{ }^{3} \mathrm{H}\right]$ testosterone (Amersham, TRK402) as tracer and rabbit-anti-testosterone-1 1-bovine serum albumin serum $\$ 250$, supplied by G. D. Niswender) as antiserum. Sensitivity of the assay was $0.15 \mathrm{ng} / \mathrm{ml}$ and intra- and interassay coefficients of variation were 6.9 and $16.2 \%$, respectively. Serially diluted deer plasma exhibited parallel binding to that of the standard curve.

Total plasma triiodothyronine (T3) was assayed by the method of Sadler \& Brownlie (1975). The assay used T3 (Sigma) in deer plasma stripped by ion-exchange resin for standard, iodinated T3 ( $\mathrm{L}-3,5,3^{\prime}-\left[{ }^{125} \mathrm{I}\right]-$-triiodothyronine, Nex-[10, Du Pont) as tracer and rabbit anti-T3-BSA conjugate (CS3-1983, Christchurch Public Hospital, NZ) as antiserum. The binding pattern of serially diluted deer samples was parallel to that of the standard curve and assay sensitivity was $0.05 \mathrm{nmol} / 1$. Inter- and intra-assay coefficients of variation were 5.4 and $3.8 \%$ respectively.

Plasma prolactin was assayed using an enzyme-linked immunosorbent assay (ELISA) (L. K. Lewis, P. A. Elder \& G. K. Barrell, unpublished). Reference standard for prolactin was NIADDK-o-PRL-16 and the assay used a rabbit anti-o-PRL antiserum (provided by D. F. M. van de Wiele). The second antibody was goat anti-rabbit immunoglobulins $\mathrm{G}$ and $\mathrm{L}$ peroxidase conjugate (Tago, California), the enzyme substrate contained $o$-phenylenediamine dihydrochloride, and the product absorbance was read at $492 \mathrm{~nm}$ with a reference wave length of $650 \mathrm{~nm}$. Crossreactivity with other pituitary hormones was less than $1 \%$ and the assay was considered specific for prolactin. 
Assay sensitivity was $2.5 \mathrm{ng} / \mathrm{ml}$ with intra- and interassay coefficients of variation of 8.5 and $15 \%$, respectively. Serially diluted deer plasma produced a change in absorbance which was parallel to the curve obtained with the ovine prolactin standards. The assay was considered to be valid for measuring prolactin in deer plasma but the values are expressed here in terms of the ovine standard.

Statistical analysis. Effects of season and thyroidectomy were examined by split-plot analysis of variance. Data for plasma concentrations of testosterone, prolactin and $\mathrm{T} 3$, and for peak testosterone concentration following GnRH injection were transformed to logarithms for analysis of variance. LH response to injection of GnRH was calculated as the incremental change between the mean of three preinjection samples and the peak postinjection concentration.

\section{Results}

\section{Responses of $\mathrm{LH}$ and testosterone to GnRH administration}

In the case of $\mathrm{LH}$ all animals responded to $10 \mu \mathrm{g} \mathrm{GnRH}$ on every occasion, but there were seasonal changes in the response (Fig. 1). In winter (July), both groups of stags exhibited similarly low responses to the stimulus, but THX stags had a greater incremental response $(P<0.01)$ than controls in the spring (October). Throughout summer and the following autumn, the mean response of $\mathrm{LH}$ to GnRH was equally high in THX and control stags. The pattern of response for testosterone was similar to that of LH except that control animals did not exhibit any response to GnRH during October and December (Fig. 1).

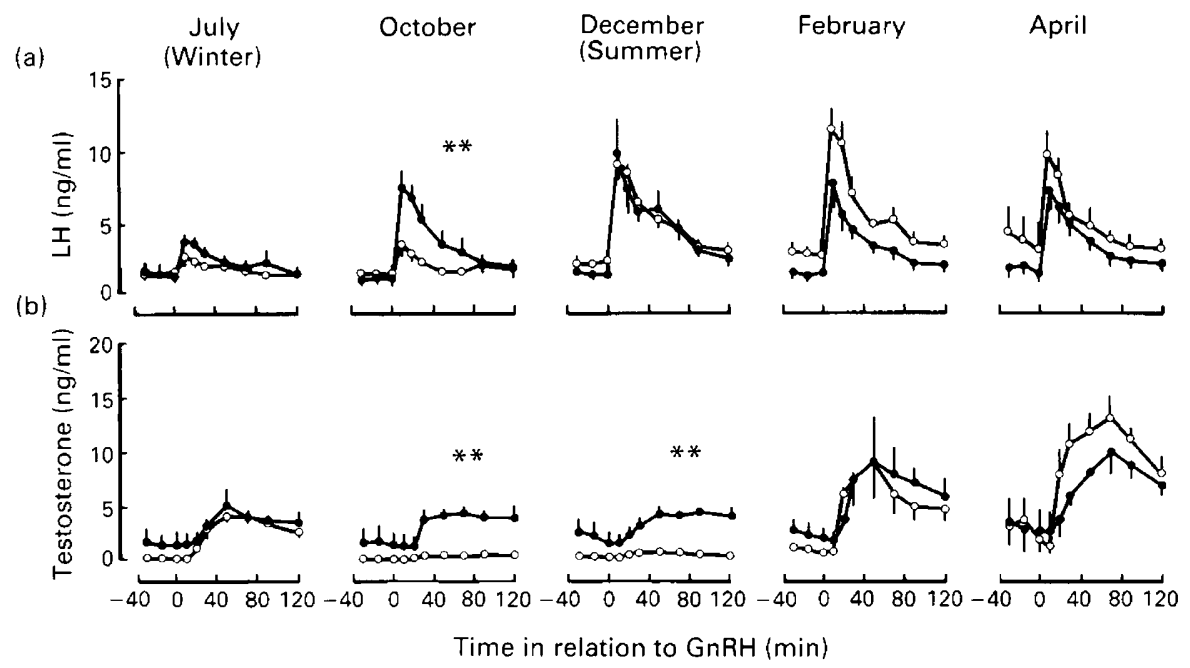

Fig. 1. Plasma concentrations of (a) luteinizing hormone ( $\mathrm{LH})$ and (b) testosterone in thyroidectomized $(\bullet, n=3)$ and intact $(\bigcirc, n=4)$ red deer stags showing response to a single i.v. dose of gonadotrophin-releasing hormone $(\mathrm{GnRH})$ (injected at $0 \mathrm{~min}$ ) on five occasions. ${ }^{* *}$ Incremental change (LH) or peak response (testosterone) following injection of $\mathrm{GnRH}$ was different between the two groups of stags, $P<0 \cdot 01$. Data are means \pm s.e.m.

\section{Testosterone, testis diameter and antler cycle}

Plasma testosterone concentration and testis diameter of both groups of stags had a successive rise and decline associated with the rutting season (February to May, 1988). In spring (September to November) the values for these parameters decreased in control stags, but not in THX stags (Fig. 2). After midsummer (December) plasma testosterone concentration and testis diameter of 
(a)
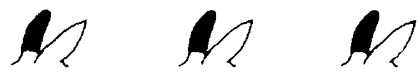

21
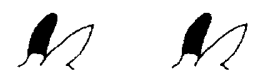

(b)
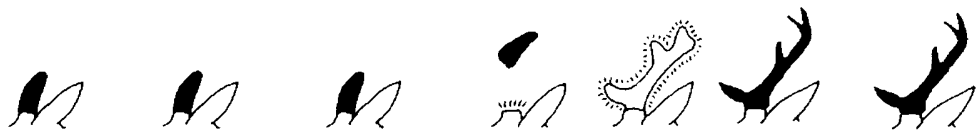

(c)
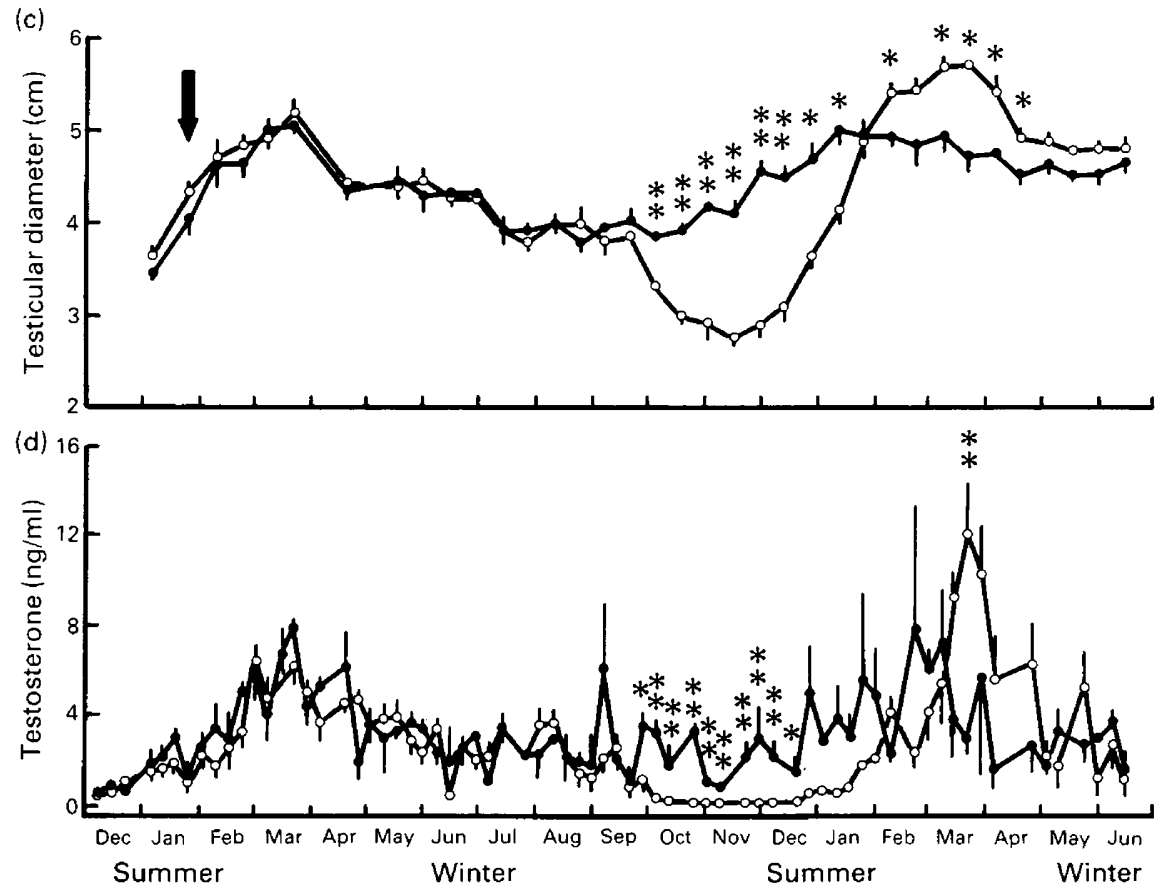

Fig. 2. Changes in the antlers of (a) thyroidectomized and (b) intact red deer stags (i.e. dead bone, casting, regrowth with velvet, cleaned antler) from December 1988 until June 1989. Fluctuations of (c) testicular diameter and (d) plasma concentration of testosterone in thyroidectomized $(\bullet, n=3)$ and intact $(O, n=4$ in (c) and 5 in (d)) red deer stags recorded at weekly intervals from December 1987 until June 1989. Arrow indicates date of thyroidectomy. Asterisks indicate significant $\left({ }^{*} P<0.05,{ }^{* *} P<0.01\right)$ differences between means for each group of stags. Data are means \pm s.e.m.

control stags increased steeply, reaching higher values than those of THX stags by the following autumn (Fig. 2).

Antlers of control stags were cast off in September-October 1988 and replaced by new sets, whereas antlers of THX stags were not cast during the study (Fig. 2).

\section{Triiodothyronine}

Plasma T3 concentration of control stags exhibited a significant $(P<0.01)$ seasonal pattern of change (Fig. 3), with higher concentrations during spring and summer and lower in autumn and winter. In the THX animals, plasma T3 concentration decreased immediately after thyroidectomy, but rose after placement of the T4 implant. Afterwards, there was a gradual decrease in plasma T3 concentration in these animals and concentrations were undetectable from June 1988 onwards. 


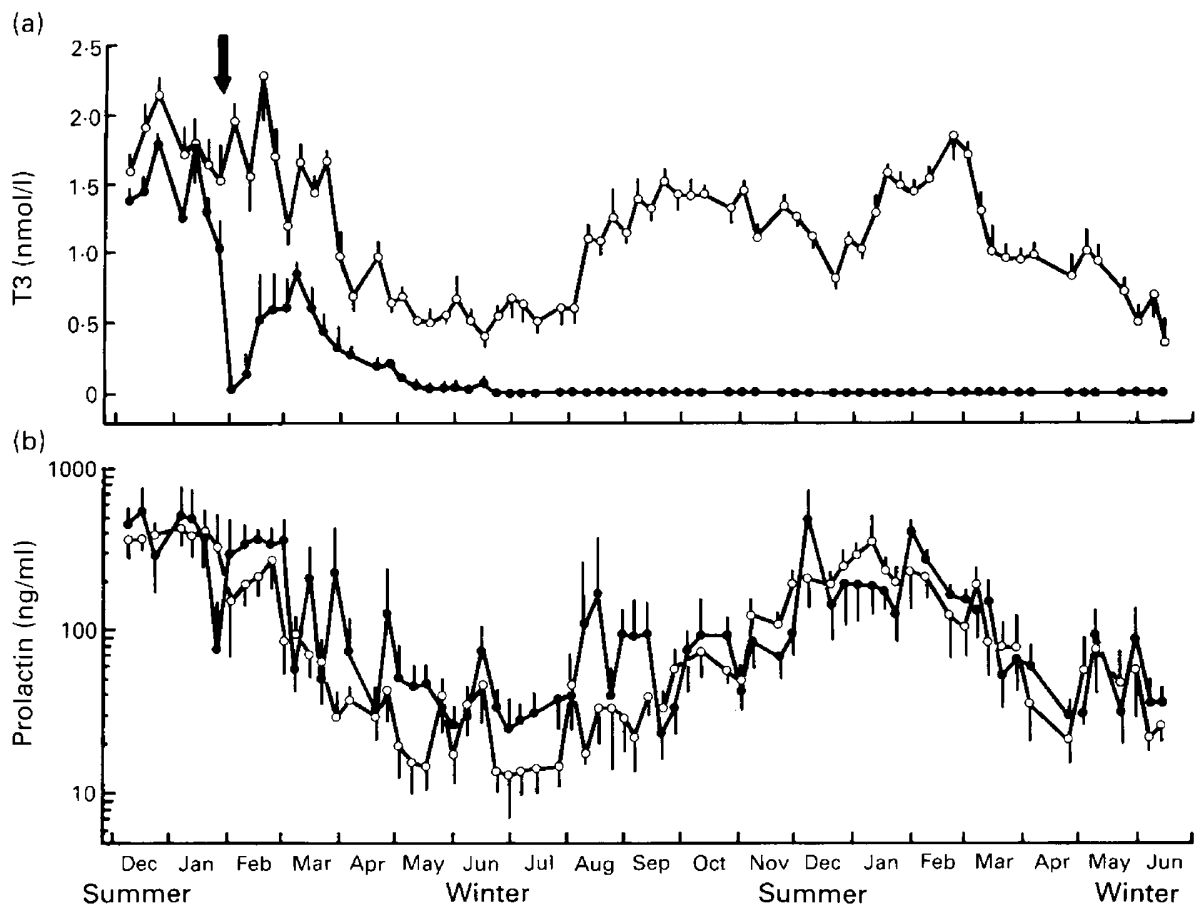

Fig. 3. Plasma concentrations of (a) triiodothyronine (T3) and (b) prolactin in thyroidectomized $(\bullet, n=3)$ and intact $(O, n=5)$ red deer stags recorded at weekly intervals from December 1987 until June 1989. Arrow indicates date of thyroidectomy. In (a), means for each group of stags are different $(P<0.01)$ from date of thyroidectomy. Data are means \pm s.e.m.

\section{Prolactin}

THX and control stags had similar patterns of plasma prolactin concentration throughout the experimental period (Fig. 3). Concentrations during summer (December to February) were higher $(P<0.05)$ than in winter (June to July).

\section{Discussion}

These results support the hypothesis that thyroid gland activity is necessary for the transition from the breeding to the nonbreeding state in seasonally breeding animals. In the present study, this is demonstrated by the persistence of testosterone concentrations in blood of THX stags in October and December, when they were barely detectable in the thyroid-intact controls. This study provides evidence for a seasonal pattern of T3 secretion, with lower plasma concentrations in winter, followed by an abrupt rise in spring and high concentrations in summer. Taken together, the results could indicate a regulatory role for the thyroid hormones during spring, which may account for the increase in secretion of $\mathrm{T} 3$ at this time of the year.

The persistence of testicular secretory activity is borne out by maintenance of post-rutting testis size and plasma testosterone concentration in the THX stags plus their retention of hard antlers. Cessation of testosterone secretion is a prerequisite for casting of antlers (Goss, 1983), but the THX stags maintained measurable plasma concentrations of testosterone, as well as detectable responses of this hormone to GnRH stimulation throughout the study, hence the continued presence of hard antlers on these animals. 
The present study extends the list of mammals in which hypothyroidism has been shown to prevent the seasonal suppression of reproductive activity. This includes sheep (Nicholls et al., 1988; Follett \& Potts, 1990; Moenter et al., 1991), golden hamster (Vriend, 1985) and mink (Jacquet et al., 1986). Previously, much of the evidence for the role of thyroid hormones in the termination of seasonal breeding activity has come from avian studies. Birds under a stimulatory photoperiod (long days) eventually exhibit sexual quiescence due to photorefractoriness (Dawson \& Goldsmith, 1982). Thyroidectomy abolishes photorefractoriness in European starlings (Wieselthier \& van Tienhoven, 1972; Goldsmith \& Nicholls, 1984) and Japanese quail (Follett \& Nicholls, 1985), and this effect of thyroidectomy can be reversed in starlings by treatment with thyroxine (Goldsmith et al., 1985). In mammals, evidence is accumulating to suggest that termination of the breeding season is an endogenously generated event (Malpaux et al., 1988), akin to the mechanism of photorefractoriness in birds, so the underlying role of the thyroid hormones in seasonal breeding may be similar in birds and mammals.

Notwithstanding these considerations, it is possible that the cessation of testicular activity in thyroid-intact stags is a response to an inhibitory effect of the onset of long daily photoperiods in spring and it could be argued that this effect requires mediation by the thyroid hormones. In sheep, pineal gland function, as determined by monitoring blood concentrations of melatonin, showed normal responses to photoperiodic changes after thyroidectomy, even though the onset of anoestrus was blocked (Nicholls et al., 1988; Moenter et al., 1991). This means that, if thyroid hormones were mediators of inhibitory photoperiods, their effect on the reproductive axis would have to be at the post-pineal level of processing.

Effects of thyroidectomy in the present study were manifested by red deer stags at pituitary and testicular levels. In intact stags, pituitary and testes have very low responses to GnRH challenge in spring and summer (Fennessy et al., 1988) or under long days (Suttie et al., 1989). In the present study, LH response to a GnRH stimulus was greater in THX stags than in controls during October (Fig. 1). The THX stags also maintained a response of plasma testosterone to the LH elevations generated by injection of GnRH, whereas thyroid-intact controls exhibited a decrease in testicular responsiveness, especially evident in spring and early summer (October and December, Fig. 1). The effects of thyroidectomy were an enhancement of the responsiveness of pituitary and testes to endocrine stimuli, which was counter to the view that lack of thyroid hormones must lead to a depression in organ function. This point was made also by Moenter et al. (1991) who showed that thyroidectomized ewes maintained the negative feedback effects of oestradiol on LH secretion, which rules out general dysfunction as a universal explanation for the effects of thyroid removal.

Seasonal patterns of secretion of the thyroid hormones have been recorded in various animals, but there is some conflict in the literature regarding the timing of peak and trough blood concentrations. For instance, in some studies of deer, blood T3 concentrations increased through spring and summer, and declined during autumn and winter. This occurred with the red deer stags in the present study, in red deer and Père David's deer hinds (Loudon et al., 1989), in male reindeer (Ryg \& Jacobsen, 1982) and white-tailed deer (Bubenik \& Leatherland, 1984). In contrast, female whitetailed deer had high serum concentrations of thyroxine in early winter and spring although the pattern for T3 was less clear (Watkins et al., 1983). Likewise, plasma thyroxine concentrations in sheep showed a peak during winter in some cases (e.g. Sutherland \& Irvine, 1974) and during summer in others (e.g. Fraser \& McNeilly, 1982). Low environmental temperature is regarded as a major stimulus for the release of thyroid hormones (Sterling \& Lazarus, 1977) and this could account for peak secretion rates in winter. Clearly, the data from the deer and some sheep studies which provide the converse pattern to this indicate that factors other than temperature have important roles in the control of circulating concentrations of thyroid hormones. Ryg \& Jacobsen (1982) and Loudon et al. (1989) recorded significant correlations between blood T3 concentration and feed intake in deer species, the major increases in T3 accompanying the massive increase in live weight during spring.

In THX red deer stags, plasma $\mathrm{T} 3$ concentrations were undetectable once the effect apparently due to the thyroxine implant had disappeared (Fig. 3) and this is useful confirmation of the 
effectiveness of the surgical operation. The implants were provided to prevent an abrupt loss of thyroid hormones following surgery. It is tempting to relate the onset of increased plasma T3 concentrations of control stags in spring with the concurrent demise of testicular activity, as exhibited by testis diameter and plasma testosterone concentration. This inverse relationship between thyroid and testicular function has been noted by other workers, e.g. in mink (BoissinAgasse et al., 1980) and red foxes (Maurel \& Boissin, 1981), and is in keeping with the lack of reduction of testicular activity in the THX stags recorded here. However, none of this provides any evidence for causality and it may be unwise to attribute a regulatory role to the rise in thyroid hormone secretion during spring.

Changes in secretion of thyroid hormones have been correlated with changes in growth of wool by sheep (Lincoln et al., 1980). In red deer stags, the spring moult was disrupted by thyroidectomy (Shi \& Barrell, 1990) and the earlier spring moulting of Père David's deer was accompanied by a correspondingly early increase in plasma T3 concentrations (Loudon et al., 1989). However, when the timing of coat growth in red deer hinds was delayed by treatment with bromocriptine, there was no effect on T3 concentration (Curlewis et al., 1988). Clearly, the issue of thyroidal regulation of coat growth in red deer is not resolved. There is evidence for a role of prolactin in seasonal coat patterns in male mammals (Lincoln, 1989) and in female red and Père David's deer (Loudon et al., 1989). The seasonal pattern of blood concentrations of prolactin in many mammals, which is associated directly with changes in daily photoperiod, has been demonstrated in red deer stags here and previously (Suttie et al., 1984; Barrell et al., 1985). However, this pattern was not disrupted by thyroidectomy in the present study or in sheep (Fraser \& McNeilly, 1982; Moenter et al., 1991). These results indicate that the effects of thyroidectomy on coat growth in red deer or sheep were not mediated by changes in prolactin secretion and that the thyroid hormones are not involved in the regulation of seasonal patterns of prolactin secretion. Secretion of thyroid stimulating hormone (TSH) and prolactin can be stimulated by a single hypothalamic factor, thyrotrophin-releasing hormone (TRH) (Fraser \& McNeilly, 1982). Consequently, there may be a relationship between the regulation of prolactin and the thyroid hormones, which might account for some of the confusion that exists about this topic.

We thank A. S. Familton for performing thyroidectomies, M. J. Keeley for skilful handling of animals and assistance in sample collection and data recording, L. K. Lewis for developing the ELISA for prolactin and valuable help with testosterone assays and J. A. Duckworth for setting up the LH assay. The following are greatly acknowledged for providing hormone assay reagents: G. D. Niswender, Colorado State University; D. F. M. van de Wiele, Research Institute for Animal Husbandry 'Schoonoord', Netherlands; A. F. Parlow, Pituitary Hormones and Antisera Center, Torrance, California; W. A. Sadler, Christchurch Public Hospital, NZ. The financial support of Z. D. Shi by the Government of the People's Republic of China is gratefully acknowledged.

\section{References}

Barrell, G.K., Muir, P.D. \& Sykes, A.R. (1985) Seasonal profiles of plasma testosterone, prolactin, and growth hormone in red deer stags. In Biology of Deer Production. pp. 185 190. Eds P. F. Fennessy \& K. R. Drew. Royal Society of New Zealand. Wellington.

Boissin-Agasse, L., Maurel, D. \& Boissin, J. (1980) Seasonal variations in thyroxine and testosterone levels in relation to the moult in the adult male mink (Mustela vison Peale and Beauvois). Can. J. Zool. 59, 1062--1066.

Bubenik, G.A. \& Leatherland, J.F. (1984) Seasonal levels of cortisol and thyroid hormones in intact and castrated mature-male white-tailed deer. Can. J. Zool. 62, 783-787.

Curlewis, J.D., Loudon, A.S.I., Milne, J.A. \& McNeilly, A.S. (1988) Effect of chronic long-acting bromocriptine treatment on live weight, voluntary food intake, coat growth and breeding season in nonpregnant red deer hinds. J. Endocr. 119, 413-420.

Dawson, A. \& Goldsmith, A.R. (1982) Prolactin and gonadotrophin secretion in wild starlings (Sturnus vulgaris) during the annual cycle and in relation to nesting, incubation and rearing young. Gen. comp. Endocr. 48, 213-221. 
Fennessy, P.F., Suttie, J.M., Crosbie, S.F., Corson, I.D., Elgar, H.J. \& Lapwood, K.R. (1988) Plasma LH and testosterone responses to gonadotrophin-releasing hormone in adult red deer (Cervus elaphus) stags during the annual antler cycle. J. Endocr. 117, 35-41.

Follett, B.K. \& Nicholls, T.J. (1985) Influences of thyroidectomy and thyroxine replacement on photoperiodically controlled reproduction in quail. J. Endocr. 107, 211-221.

Follett, B.K. \& Potts, C. (1990) Hypothyroidism affects reproductive refractoriness and the seasonal oestrous period in Welsh mountain ewes. J. Endocr. 127, 103-109.

Fraser, H.M. \& McNeilly, A.S. (1982) Effect of chronic immunoneutralization of thyrotropin-releasing hormone on the hypothalamic pituitary-thyroid axis, prolactin, and reproductive function in the ewe. Endocrinology 111, 1964-1973.

Garnier, D.H., Cotta, Y. \& Terqui, M. (1978) Androgen radioimmunoassay in the ram: results of direct plasma testosterone and dehydroepiandrosterone measurement and physiological evaluation. Ann. Biol. anim. Biochim. Biophys. 18, 265-281.

Goldsmith, A.R. \& Nicholls, T.J. (1984) Thyroidectomy prevents the development of photorefractoriness and the associated rise in plasma prolactin in starlings. Gen. comp. Endocr. 54, 256263.

Goldsmith, A.R., Nicholls, T.J. \& Plowman, G. (1985) Thyroxine treatment facilitates prolactin secretion and induces a state of photorefractoriness in thyroidectomized starlings. J. Endocr. 104, 99-103.

Goodman, R.L., Bittman, E.L., Foster, D.L. \& Karsch, F.J. (1982) Alterations in the control of luteinizing hormone pulse frequency underlie the seasonal variation in estradiol negative feedback in the ewe. Biol. Reprod. 27, 580 589.

Goss, R.J. (1983) Deer Antlers: Regeneration, Function, and Evolution. Academic Press, NY.

Gwinner, E. (1986) Circannual Rhythms. Springer Verlag, Berlin.

Jacquet, J.-M., Coutant, C., Maurel, D., Boissin-Agasse, L. \& Boissin, J. (1986) Influence de la thyroidectomie sur les variations, au cours du printemps et de l'été, de l'activité testiculaire et de la prolactinémie chez le vison. C. r. hebd. Séanc. Acad. Sci. Paris D 303, 367-370.

Karsch, F.J. \& Wayne, N.L. (1988) Interplay of endogenous rhythms and environmental cues in organizing the seasonal reproductive cycle of the ewe. Proc. 11th Int. Congr. Anim. Reprod. \& AI, Dublin 5, 22I-227.

Karsch, F.J., Bittman, E.L., Foster, D.L., Goodman, R.L., Legan, S.J. \& Robinson, J.E. (1984) Neuroendocrine basis of seasonal reproduction. Recent Prog. Horm. Res. 40, 185-232.

Kelly, R.W., McNatty, K.P., Moore, G.H., Ross, D. \& Gibb, M. (1982) Plasma concentration of LH, prolactin, oestradiol and progesterone in female red deer (Cervus elaphus) during pregnancy. J. Reprod. Fert. 64, 475-483.

Legan, S.J., Karsch, F.J. \& Foster, D.L. (1977) The endocrine control of seasonal reproductive function in the ewe: a marked change in response to the negative feedback action of estradiol on luteinizing hormone secretion. Endocrinology 101, 818-824.

Lincoln, G.A. (1989) Significance of seasonal cycles in prolactin secretion in male mammals. In Perspectives in Andrology, pp. 299-306. Ed. M. Serio. Raven Press, NY.

Lincoln, G.A. \& Short, R.V. (1980) Seasonal breeding: Nature's contraceptive. Recent Prog. Horm. Res. 36, I-52.

Lincoln, G.A., Klandorf, H. \& Anderson, N. (1980) Photoperiodic control of thyroid function and wool and horn growth in rams and the effect of cranial sympathectomy. Endocrinology 107, 1543-1548.

Loudon, A.S.I., Milne, J.A., Curlewis, J.D. \& McNeilly, A.S. (1989) A comparison of the seasonal hormone changes and patterns of growth, voluntary food intake and reproduction in juvenile and adult red deer (Cervus elaphus) and Père David's deer (Elaphurus davidianus) hinds. J. Endocr. 122, 733-745.

Malpaux, B., Wayne, N.L. \& Karsch, F.J. (1988) Termination of the breeding season in the Suffolk ewe: involvement of an endogenous rhythm of reproduction. Biol. Reprod. 39, 254-263.

Maurel, D. \& Boissin, J. (1981) Plasma thyroxine and testosterone levels in the red fox (Vulpes vulpes L.) during the annual cycle. Gen. comp. Endocr. 43, 402-404.

Moenter, S.M., Woodfill, C.J.I. \& Karsch, F.J. (1991) Role of the thyroid gland in seasonal reproduction: thyroidectomy blocks seasonal suppression of reproductive neuroendocrine activity in ewes. Endocrinology 128, 1337-1344.

Nicholls, T.J., Follett, A.R., Goldsmith, A.R. \& Pearson, H. (1988) Possible homologies between photorefractoriness in sheep and birds: the effect of thyroidectomy on the length of the ewe's breeding season. Reprod. Nutr. Develop. 28, 375-385.

Ryg, M. \& Jacobsen, E. (1982) Seasonal changes in growth rate, feed intake, growth hormone, and thyroid hormones in young male reindeer (Rangifer tarandus tarandus). Can. J. Zool. 60, 15-23.

Sadler, W.A. \& Brownlie, B.E.W. (1975) Triiodothyronine radioimmunoassay in the assessment of thyroid function. $N Z$ med. J. 81, 328-334.

Schanbacher, B.D. \& D'Occhio, M.J. (1982) Validation of a direct radioimmunoassay for testosterone in unextracted serum from five species: application to study of the hypothalamic-pituitary-gonadal axis in males. J. Androl. 3, 45-51.

Shi, Z.D. \& Barrell, G.K. (in press) Effects of thyroidectomy on seasonal patterns of live weight, testicular function, antler development and molting in red deer stags. In Proc. 2nd Int. Symp. Biol. Deer. Ed. R. D. Brown. Springer Verlag, New York.

Sterling, K. \& Lazarus, J.H. (1977) The thyroid and its control. A. Rev. Physiol. 39, 349-371.

Sutherland, R.L. \& Irvine, C.H.G. (1974) Effect of season and pregnancy on total plasma thyroxine concentrations in sheep. Am. J. vet. Res. 35, 311-312.

Suttie, J.M., Lincoln, G.A. \& Kay, R.N.B. (1984) Endocrine control of antler growth in red deer stags. J. Reprod. Fert. 71, 7-15.

Suttie, J.M., Fennessy, P.F., Corson, I.D., Laas, F.J., Elgar, H.J. \& Lapwood, K.R. (1989) LH and testosterone responses to $\mathrm{GnRH}$ in red deer (Cervus elaphus) stags kept in a manipulated photoperiod. $J$. Reprod. Fert. 85, 213-219.

Vriend, J. (1985) Effects of melatonin and thyroxine replacement on thyrotropin, luteinizing hormone, 
and prolactin in male hypothyroid hamsters. Endocrinology 117, 2402-2407.

Watkins, B.E., Ullrey, D.E., Nachreiner, R.F. \& Schmitt, S.M. (1983) Effects of supplemental iodine and season on thyroid activity of white-tailed deer. $J$. Wildl. Mgmi 47, 45-58.
Wieselthier, A.S. \& van Tienhoven, A. (1972) The effect of thyroidectomy on testicular size and on the photorefractory period in the starling (Sturnus vulgaris L.). J. exp. Zool. 179, 331-338.

Received 24 December 1990 